\title{
Neonatal and Maternal Outcomes With Prolonged Second Stage of Labor
}

S. Katherine Laughon, M.D., M.S. ${ }^{1}$, Vincenzo Berghella, M.D. ${ }^{2}$, Uma M. Reddy, M.D.,M.P.H. ${ }^{3}$, Rajeshwari Sundaram, Ph.D. ${ }^{4}$, Zhaohui Lu, M.S. ${ }^{5}$, and Matthew K Hoffman, M.D., M.P.H. ${ }^{6}$ ${ }^{1}$ Epidemiology Branch, Division of Intramural Population Health Research, Eunice Kennedy Shriver National Institute of Child Health and Human Development, National Institutes of Health, 6100 Executive Blvd Room 7B03, Bethesda, MD 20892, U.S.A.

2Division of MFM, Department of Obstetrics and Gynecology, Thomas Jefferson University, 834 Chestnut Street, Suite 400, Philadelphia, PA 19107, U.S.A.

${ }^{3}$ Pregnancy and Perinatology Branch, Eunice Kennedy Shriver National Institute of Child Health and Human Development, National Institutes of Health, 6100 Executive Blvd Room 4B03, Bethesda, MD 20892, U.S.A.

${ }^{4}$ Biostatistics and Bioinformatics Branch, Division of Intramural Population Health Research, Eunice Kennedy Shriver National Institute of Child Health and Human Development, National Institutes of Health, 6100 Executive Blvd Room 7B03, Bethesda, MD 20892, U.S.A.

${ }^{5}$ Glotech, Inc., Division of Intramural Population Health Research, Eunice Kennedy Shriver National Institute of Child Health and Human Development, National Institutes of Health, 6100 Executive Blvd Room 7B03, Bethesda, MD 20892, U.S.A.

${ }^{6}$ Division of Education \& Research Department of Obstetrics and Gynecology, Christiana Care Health System, 4755 Ogletown-Stanton Road, Newark DE 19718, USA

\section{Abstract}

Objective-To assess neonatal and maternal outcomes when when the second stage of labor was prolonged according to American College of Obstetricians and Gynecologists guidelines.

Methods-Electronic medical record data from a retrospective cohort (2002-2008) from 12 U.S. clinical centers (19 hospitals), including 43,810 nulliparous and 59,605 multiparous singleton deliveries $\geq 36$ weeks, vertex presentation, who reached $10 \mathrm{~cm}$ cervical dilation were analyzed. Prolonged second stage was defined as: nulliparous women with epidural $>3$ hours, without $>2$ hours; multiparous women with epidural $>2$ hours, without $>1$ hour. Maternal and neonatal

Corresponding Author: S. Katherine Laughon, MD, MS; Epidemiology Branch, Division of Intramural Population Health Research, Eunice Kennedy Shriver National Institute of Child Health and Human Development, National Institutes of Health, Bethesda MD, 6100 Executive Blvd Room 7B03, Bethesda, MD 20892. Office: (301) 435-6935. Fax: (301) 402-2084. laughonsk@mail.nih.gov.

Financial Disclosure: The authors did not report any potential conflicts of interest.

For a list of institutions involved in the Consortium, please see the Appendix online at http://links.lww.com/xxx.

Presented at the Annual Society for Maternal-Fetal Medicine Meeting, San Francisco, CA, February 14, 2013. 
outcomes were compared and adjusted odds ratios calculated controlling for maternal race, BMI, insurance, and region.

Results-Prolonged second stage occurred in $9.9 \%$ and $13.9 \%$ of nulliparous and $3.1 \%$ and $5.9 \%$ of multiparous women, with and without an epidural, respectively. Vaginal delivery rates with prolonged second stage compared to within guidelines were $79.9 \%$ versus $97.9 \%$ and $87.0 \%$ versus $99.4 \%$ for nulliparous women with and without epidural, respectively, and $88.7 \%$ versus $99.7 \%$ and $96.2 \%$ versus $99.9 \%$ for multiparous women with and without epidural, respectively ( $P<.001$ for all comparisons). Prolonged second stage was associated with increased chorioamnionitis and third-degree or fourth-degree perineal lacerations. Neonatal morbidity with prolonged second stage included sepsis in nulliparous women [with epidural: $2.6 \%$ versus $1.2 \%$ (AOR 2.08; 95\%CI 1.60-2.70); without epidural: $1.8 \%$ versus $1.1 \%$ (AOR 2.34; 95\%CI $1.28-$ 4.27)]; asphyxia in nulliparous women with epidural [0.3\% versus $0.1 \%$, AOR 2.39 ; $95 \%$ CI $1.22-$ 4.66]; and perinatal mortality without epidural [0.18\% versus $0.04 \%$ for nulliparous women (AOR 5.92; 95\% CI $1.43-24.51$ )] and $0.21 \%$ versus $0.03 \%$ for multiparous women (AOR 6.34; 95\%CI 1.32-30.34)]. However, among the offspring of women with epidurals whose second stage was prolonged (3,533 nulliparous and 1,348 multiparous women), there were no cases of hypoxic ischemic encephalopathy or perinatal death.

Conclusions-Benefits of increased vaginal delivery should be weighed against potential small increases in maternal and neonatal risks with prolonged second stage.

\section{INTRODUCTION}

Historical guidance for the 2-hour rule of the second stage of labor to prevent maternal and neonatal morbidity and mortality was introduced in the mid-1800s by expert opinion and case series publications. (1) Hamilton published findings where no stillbirths occurred when forceps were used to shorten the second stage, and perhaps was the first to publish the 2hour rule based on his observations. $(2,3)$ Since that time, studies have found increased duration to be associated with increased risk of maternal morbidity primarily hemorrhage, fever or infection, and perineal trauma. (4-10) The association of neonatal risks with a prolonged second stage has been controversial. Recent studies have found an increased risk of Apgar score < 7 (9-11), neonatal intensive care unit (NICU) admission $(11,12)$, birth depression and minor trauma (10), while other studies have found no differences in neonatal outcomes including more serious complications such as seizures or sepsis. (4-8) Rare neonatal morbidities including asphyxia, hypoxic-ischemic encephalopathy and mortality have been understudied. Therefore, whether the prolongation of the second stage of labor beyond the currently accepted windows to achieve a vaginal delivery (and avoid the risks of cesarean delivery) results in serious neonatal complications has remained unclear. Given the lack of well-powered studies with detailed clinical data, as well as the common use of epidural, determination of the optimal length of the second stage is needed. (13)

The aims of this study were to quantitate the chance of vaginal delivery for prolonged second stage and to evaluate both maternal and fetal and neonatal risks associated with such prolongations. 


\section{MATERIALS AND METHODS}

The Consortium on Safe Labor (CSL) was conducted by the Eunice Kennedy Shriver National Institute of Child Health and Human Development, National Institutes of Health to determine the course of labor associated with optimal maternal and neonatal outcomes. The CSL was a retrospective study of 208,695 women with 228,438 deliveries from 12 clinical centers and 19 hospitals representing nine College districts from 2002-2008. (14) Institutional Review Board approval was obtained by all participating institutions. Detailed information from the patient electronic medical record was extracted including demographic data, and medical, prenatal, and antenatal histories. Labor and delivery information including cervical examinations and timing were obtained. Postpartum maternal and neonatal outcomes were collected along with maternal and newborn discharge summaries. Validation of four key variables was performed, including cesarean for nonreassuring fetal heart rate tracing, asphyxia, NICU admission for respiratory conditions, and shoulder dystocia. The electronic medical records were highly accurate with $>91 \%$ concordance for all subgroups and $>95 \%$ for most (see prior publication for more details). (14)

The objectives of this study were to quantitate the chance of vaginal delivery once American College of Obstetricians and Gynecologists (the College) guidelines for duration of second stage were exceeded and to compare both maternal and fetal and neonatal risks for deliveries within the guidelines to those outside of the guidelines.

Length of second stage of labor was determined by subtracting the date and time of delivery from the date and time of $10 \mathrm{~cm}$ cervical dilation as recorded in the maternal medical record. Duration of second stage outside College guidelines was designated as prolonged second stage, and defined as: for nulliparous women $>3$ hours with epidural or $>2$ hours without; multiparous women $>2$ hours with epidural or $>1$ hour without. (15) Otherwise, delivery was designated as within guidelines. Success of any vaginal delivery (including nonoperative and operative) was estimated, as well as operative vaginal delivery (forceps, vacuum, forceps and vacuum, or unspecified). Maternal outcomes were explored individually as well as a composite that included postpartum hemorrhage, blood transfusion, cesarean hysterectomy, endometritis, or intensive care unit admission (ICU). Postpartum hemorrhage was defined as estimated blood loss $>500 \mathrm{ml}$ for vaginal delivery and $>1000$ $\mathrm{ml}$ for cesarean delivery. Other maternal outcomes included chorioamnionitis, wound infection, wound separation, episiotomy, $3^{\text {rd }}$ or $4^{\text {th }}$ degree perineal laceration, cervical laceration and hospital length of stay. Neonatal outcomes were explored individually as well as a composite that included shoulder dystocia, 5 minute Apgar $<4$, need for continuous positive airway pressure (CPAP) resuscitation or higher, neonatal intensive care unit (NICU) admission, sepsis, pneumonia, hypoxic-ischemic encephalopathy/ periventricular leukomalacia (HIE/PVL), seizure, intracranial hemorrhage/periventricular hemorrhage $(\mathrm{ICH} / \mathrm{PVH})$, asphyxia, or perinatal death as recorded in the medical record and supplemented with discharge ICD-9 diagnoses. Not all sites reported all of the outcomes, so individual analyses of secondary outcomes were limited to those sites where reported.

We included singleton births $(\mathrm{n}=223,394)$ delivering $\geq 36$ weeks of gestation $(\mathrm{n}=206,920)$. The following were then excluded: nonvertex presentation $(n=26,382)$, antepartum stillbirth 
prior to the onset of labor $(n=238)$, prior uterine $\operatorname{scar}(n=21,604)$ and congenital anomalies $(\mathrm{n}=8901)$. Cervical exams prior to vaginal delivery were $<10 \mathrm{~cm}$ for 22,291 and missing for 3461 deliveries, and cervical examinations prior to cesarean delivery were $<10 \mathrm{~cm}$ for 13,772 and missing for 6779 deliveries leaving a total of 103,492 deliveries with a cervical dilation of $10 \mathrm{~cm}$ recorded in the medical record. We excluded $77(0.2 \%)$ deliveries with a $2^{\text {nd }}$ stage $\geq 12$ hours as these were considered most likely to be an error The final analysis included 43,810 nulliparous and 59,605 multiparous deliveries.

Maternal, obstetric, and neonatal characteristics and outcomes were compared using either linear (continuous or categorical variables) or logistic (binary variables) regression with generalized estimating equations to account for multiple pregnancies contributed by the same woman. Results are presented as $P$ values or odds ratios (ORs). Adjusted odds ratios (AOR) for outcomes were also calculated controlling for maternal race, BMI, insurance, and region. All statistical analyses were performed using SAS 9.3 software (SAS Institute Inc., Cary, North Carolina, US).

\section{RESULTS}

Of the 43,810 nulliparous women, $81.4 \%$ had an epidural and $10.6 \%$ delivered after a prolonged second stage. Of the 59,605 multiparous women, $72.9 \%$ had an epidural and 3.9\% delivered after a prolonged second stage. (Table 1) For the women delivering after a prolonged second stage, the majority delivered within the subsequent hour. Women who delivered after a prolonged second stage on average tended to be older and have a slightly higher BMI only if they had an epidural (Table 2). A lower proportion of women delivered after a prolonged second stage at non-teaching community hospitals. Women without an epidural presented with more favorable cervical examinations on admission and received less oxytocin (Table 2).

Vaginal delivery after prolonged second stage for nulliparous women with epidural was $79.9 \%$ versus $97.9 \%$ for women delivering within guidelines, $P<.001$; without epidural $87.0 \%$ versus $99.4 \%$ for prolonged versus within guidelines, $P<.001$, which remained significant after adjustment (Figure 1, Panel A). Rates of operative vaginal delivery for women who delivered after a prolonged second stage were at least 2-fold higher for nulliparous women (with an epidural, prolonged second stage versus within guidelines $23.0 \%$ versus $12.2 \%, P<.001$; AOR 2.23 (95\% CI 2.04-2.45) and without epidural, prolonged second stage versus within guidelines $16.0 \%$ versus $6.2 \%, P<.001$; AOR 2.89 (95\% CI 2.30-3.63) (Figure 1, Panel B). Cesarean deliveries in the second stage for women after a prolonged second stage were more likely to be performed for indications of dystocia or cephalopelvic disproportion instead of non-reassuring fetal heart rate tracing (Table 3).

Composite maternal morbidity was higher for nulliparous women with an epidural who delivered after prolonged second stage [8.4\% versus $6.1 \%, P<.001$; AOR $1.42(95 \%$ CI $1.25-$ 1.62)] (Figure 1, Panel C). Specific morbidities were increased for nulliparous women who delivered after a prolonged second stage with an approximately 3-fold higher rate of chorioamnionitis as well as increased odds of episiotomy, $3^{\text {rd }}$ or $4^{\text {th }}$ degree perineal laceration, and a one day longer median hospital stay (Table 3). Nulliparous women with an 
epidural who delivered after a prolonged second stage had additional increased rates of endometritis [1.2\% versus $0.4 \%, P<.001$; AOR 3.21 (95\% CI 2.25-4.57)], wound separation [0.2\% versus $0.02 \%, P<.001$; AOR 12.13 (95\%CI 3.63-40.46)], and postpartum hemorrhage [5.9\% versus 3.7\%, $P<.001$; AOR 1.50 (95\% CI 1.27-1.78)], but a lower rate of maternal ICU admission $(0.2 \%$ versus $0.5 \%, P=.048)$ that did not remain significant after adjustment [AOR 0.49 (95\%CI 0.20-1.21)] (Table 2). Nulliparous women without an epidural who delivered with a prolonged second stage had a higher rate of postpartum hemorrhage $(5.1 \%$ versus $3.9 \%, P=.04)$ that did not remain significant after adjustment [AOR $1.25(95 \% \mathrm{CI}$ $0.87-1.80)]$ (Table 3$)$.

In multiparous women with a prolonged second stage compared to women who delivered within guidelines, vaginal delivery occurred in $88.7 \%$ versus $99.7 \%(P<.001)$ of women with an epidural and $96.2 \%$ versus $99.9 \%(P<.001)$ of multiparous women without an epidural which remained significant after adjustment (Figure 1, Panel A). Rates of operative vaginal delivery for women who delivered after a prolonged second stage were at least 3fold higher (with an epidural, prolonged second stage versus within guidelines $9.5 \%$ versus $3.8 \%, P<.001$; AOR 3.26 (95\% CI 2.66-3.99) and without epidural, prolonged second stage versus within guidelines $4.6 \%$ versus $1.4 \%, P<.001$; AOR 3.20 (95\%CI 2.12-4.83)) (Figure 1, Panel B).

Composite maternal morbidity rates were not higher for multiparous women with prolonged second stage overall, but there was an increased odds for multiparous women with an epidural after adjustment (AOR 1.52 (95\%CI 1.17-1.97) (Figure 1, Panel C). Multiparous women who delivered with prolonged second stage regardless of epidural status had higher rates of chorioamnionitis, and higher odds of postpartum hemorrhage and $3^{\text {rd }}$ or $4^{\text {th }}$ degree perineal laceration after adjustment.

Overall, composite neonatal morbidity rates for deliveries with prolonged second stage were $11 \%$ for nulliparous women and $9 \%$ for multiparous women, which were approximately 2 $3 \%$ higher absolute rates compared to deliveries within guidelines (Figure 1, Panel D). Neonates born after a prolonged second stage were also 1.35 to 1.85 -fold more likely to be admitted to the NICU (Tables 3 and 4). Rates of neonatal sepsis were approximately double for nulliparous women with prolonged second stage regardless of epidural. Additionally, for deliveries with prolonged second stage, neonates had an approximately 2.5 -fold increased odds of 5 minute Apgar score $<4$ for nulliparous women and multiparous women with an epidural (Tables 3-4). In multiparous women without an epidural, shoulder dystocia was higher (2.2\% versus $1.7 \%$, AOR 1.78 (95\%CI 1.02-3.09). The rates of ICH/PVH were increased for nulliparous women who delivered after prolonged second stage without an epidural ( $0.3 \%$ versus $0.1 \%, P=.044$; OR 4.67 (95\% CI 1.04-20.90), although the outcome was too rare for an adjusted analysis. Asphyxia rates were increased for nulliparous women who delivered after prolonged second stage with an epidural [0.3\% versus $0.1 \%, P=.024$; AOR 2.39 (95\%CI 1.22-4.66)]. Asphyxia rates were not different for multiparous women who delivered outside the guidelines, regardless of epidural status.

Perinatal mortality was a rare outcome and for deliveries with an epidural was not different for women after prolonged second stage for either parity. For deliveries without an epidural, 
perinatal mortality was increased for women after prolonged second stage in both nulliparous women $[0.18 \%$ versus $0.04 \%$, AOR 5.92 (95\%CI 1.43-24.51)] and multiparous women [0.21\% versus $0.03 \%$, AOR 6.34 (95\%CI 1.32-30.34)].

In an analysis limited to nulliparous women with an epidural with a non-operative vaginal delivery, for women who delivered with prolonged second stage we observed results in the same direction although not all associations remained significant in this subset of women: maternal composite outcome AOR 1.23 (95\% CI 0.99-1.46, endometritis AOR 2.30 (95\%CI 1.27-4.15), postpartum hemorrhage AOR 1.45 (95\%CI 1.15-1.83), chorioamnionitis AOR 2.63 (95\%CI 2.19-3.15), $3^{\text {rd }} / 4^{\text {th }}$ degree laceration AOR 1.97 (95CI\% 1.64-2.37), as well as neonatal composite outcome AOR 1.39 (95\% CI 1.17-1.65), shoulder dystocia (1.62 (95\%CI 1.17-1.65), 5 minute Apgar < 4 AOR 2.58 (95\%CI 1.07-6.17), NICU admission AOR 1.25 (95\% CI 1.02-1.53) and neonatal sepsis AOR 2.01 (95\% CI 1.39-2.91). These results suggest that increased morbidity with prolonged second stage was not fully explained by the mode of delivery.

\section{DISCUSSION}

In this large, U.S. multicenter cohort study, we found that maternal morbidity was increased for deliveries with prolonged second stage. Given the large sample size in our study with detailed clinical detail, we were also able to demonstrate an increased risk in neonatal morbidity in all deliveries, most concerning for a $0.2 \%$ absolute increased risk of neonatal asphyxia in nulliparous women with an epidural, and a $0.14 \%$ for nulliparous women and $0.18 \%$ for multiparous women increased risk in perinatal mortality for deliveries without an epidural.

The vaginal delivery rates that we observed in deliveries for prolonged second stage duration were similar to previously reported success rates from single institutions of $83 \%$ (9) and 93\% (11) of nulliparous women delivered vaginally within 3 hours and 90\% (16) of multiparous women delivered vaginally within 1-2 hours, although were not directly comparable as those studies did not stratify by epidural status. Our vaginal delivery rates were also similar to a secondary analysis of a clinical trial of fetal pulse oximetry trial where $88 \%$ of nulliparous women delivered within 3 hours, regardless of epidural status. (12)

Increased maternal morbidities were generally consistent with reports from previous studies including postpartum hemorrhage, maternal febrile morbidity/infection and perineal trauma. (4-10) It was reassuring that we did not observe significantly increased risks for other serious maternal complications including need for blood transfusion, cesarean hysterectomy, or ICU admission. Specific neonatal risks associated with a prolonged second stage similar to previously reported included an increased risk of 5 minute Apgar score $<4$ (except nulliparous women without an epidural; note Apgar score $<7$ in the literature) and neonatal intensive care unit (NICU) admission (9-12). In contrast to studies that found no differences in neonatal outcomes including more serious complications such as seizures or sepsis (4-8), we observed a doubling of the rates of neonatal sepsis (except in multiparous women without an epidural. Novel findings included an increased risk of neonatal asphyxia for second stage of labor that exceeded College guidelines in nulliparous women, and a 6-fold 
increase in perinatal mortality for deliveries without an epidural even though overall absolute rates for both outcomes were low $(<0.5 \%)$.

The mechanism for increased morbidity cannot necessarily be attributed to the duration of $2^{\text {nd }}$ stage, as the underlying reasons for longer duration may also contribute to morbidity. For example, chorioamnionitis and increased fetal size are associated with both longer labor duration and increased maternal and neonatal morbidity. (17-19) Complications may also have been partly due to the increased in operative vaginal delivery, but our findings in a sensitivity analysis that morbidity was increased even among nulliparous women with a non-operative delivery indicates that prolonged duration of $2^{\text {nd }}$ stage may be an independent risk for morbidity. (15) The reason that perinatal mortality was increased only in deliveries without an epidural is also unknown, but perhaps prolonged second stage attributed to epidural use is associated with less risk than prolonged second stage due to other pathways.

Our study was limited by lack of data on delayed versus active pushing which has been shown to have a mean increase of 57 minutes in the second stage in a meta-analysis; however, delayed pushing has been associated with increased maternal febrile morbidity and decreased umbilical cord $\mathrm{pH}$ in some studies indicating that duration itself may be important. (20) A randomized control trial of delayed versus active pushing would be useful to study the impact on duration of second stage on maternal and neonatal outcomes There is also the possibility that some of our findings were false positives given the large number of comparisons. Caution is also warranted given the retrospective data and lack of information on long term maternal outcomes including incontinence and childhood neurologic impairment. Nonetheless, the major strength of our study was the large numbers from multiple institutions across the U.S. with rich patient level data allowing us to investigate rare neonatal morbidities at term.

We found that prolonged second stage was associated with highly successful vaginal delivery rates, but with small increases in maternal and serious neonatal morbidity, as well as perinatal mortality in deliveries without an epidural. However, it was reassuring that for mothers with an epidural who comprised the large majority of our cohort, there was no increased risk of perinatal death or HIE in association with prolonged second stage. Benefits of vaginal delivery need to be weighed against increased maternal and neonatal risks when considering duration of second stage outside College guidelines.

\section{Supplementary Material}

Refer to Web version on PubMed Central for supplementary material.

\section{Acknowledgments}

Supported by the Intramural Research Program of the National Institutes of Health, Eunice Kennedy Shriver National Institute of Child Health and Human Development (NICHD). The Consortium on Safe Labor was funded by the Intramural Research Program of the NICHD, through Contract No. HHSN267200603425C. 


\section{REFERENCES}

1. Hellman LM, Prystowsky H. The duration of the second stage of labor. Am J Obstet Gynecol. 1952 Jun; 63(6):1223-1233. [PubMed: 14933479]

2. Hamilton G. On mortality from the use of forceps. British and Foreign Med Chir Rev. 1853; 11:511.

3. Hamilton G. On the proper management of tedious labors. British and Foreign Med Chir Rev. 1871; 48:449.

4. Cohen WR. Influence of the duration of second stage labor on perinatal outcome and puerperal morbidity. Obstet Gynecol. 1977 Mar; 49(3):266-269. [PubMed: 300151]

5. Moon JM, Smith CV, Rayburn WF. Perinatal outcome after a prolonged second stage of labor. J Reprod Med. 1990 Mar; 35(3):229-231. [PubMed: 2325032]

6. Saunders NS, Paterson CM, Wadsworth J. Neonatal and maternal morbidity in relation to the length of the second stage of labour. Br J Obstet Gynaecol. 1992 May; 99(5):381-385. [PubMed: 1622909]

7. Menticoglou SM, Manning F, Harman C, Morrison I. Perinatal outcome in relation to second-stage duration. Am J Obstet Gynecol. 1995 Sep; 173(3 Pt 1):906-912. [PubMed: 7573267]

8. Myles TD, Santolaya J. Maternal and neonatal outcomes in patients with a prolonged second stage of labor. Obstet Gynecol. 2003 Jul; 102(1):52-58. [PubMed: 12850607]

9. Cheng YW, Hopkins LM, Caughey AB. How long is too long: Does a prolonged second stage of labor in nulliparous women affect maternal and neonatal outcomes? Am J Obstet Gynecol. 2004 Sep; 191(3):933-938. [PubMed: 15467567]

10. Allen VM, Baskett TF, O'Connell CM, McKeen D, Allen AC. Maternal and perinatal outcomes with increasing duration of the second stage of labor. Obstet Gynecol. 2009 Jun; 113(6):12481258. [PubMed: 19461419]

11. Cheng YW, Hopkins LM, Laros RK Jr, Caughey AB. Duration of the second stage of labor in multiparous women: maternal and neonatal outcomes. Am J Obstet Gynecol. 2007 Jun; 196(6):585 e1-585 e6. [PubMed: 17547906]

12. Rouse DJ, Weiner SJ, Bloom SL, Varner MW, Spong CY, Ramin SM, et al. Second-stage labor duration in nulliparous women: relationship to maternal and perinatal outcomes. Am J Obstet Gynecol. 2009 Oct; 201(4):357 e1-357 e7. [PubMed: 19788967]

13. Laughon SK, Branch DW, Beaver J, Zhang J. Changes in labor patterns over 50 years. Am J Obstet Gynecol. 2012 May; 206(5):419 e1-419 e9. [PubMed: 22542117]

14. Zhang J, Troendle J, Reddy UM, Laughon SK, Branch DW, Burkman R, et al. Contemporary cesarean delivery practice in the United States. Am J Obstet Gynecol. 2010 Oct; 203(4):326 e1326 e10. [PubMed: 20708166]

15. ACOG Practice Bulletin No. 17. Operative vaginal delivery. 2000

16. Bleich AT, Alexander JM, McIntire DD, Leveno KJ. An analysis of second-stage labor beyond 3 hours in nulliparous women. Am J Perinatol. 2012 Oct; 29(9):717-722. [PubMed: 22644830]

17. Duff P, Sanders R, Gibbs RS. The course of labor in term patients with chorioamnionitis. Am J Obstet Gynecol. 1983 Oct 15; 147(4):391-395. [PubMed: 6624808]

18. Piper JM, Bolling DR, Newton ER. The second stage of labor: factors influencing duration. Am J Obstet Gynecol. 1991 Oct; 165(4 Pt 1):976-979. [PubMed: 1951566]

19. Yoder PR, Gibbs RS, Blanco JD, Castaneda YS, St Clair PJ. A prospective, controlled study of maternal and perinatal outcome after intra-amniotic infection at term. Am J Obstet Gynecol. 1983 Mar 15; 145(6):695-701. [PubMed: 6829656]

20. Tuuli MG, Frey HA, Odibo AO, Macones GA, Cahill AG. Immediate compared with delayed pushing in the second stage of labor: a systematic review and meta-analysis. Obstet Gynecol. 2012 Sep; 120(3):660-668. [PubMed: 22872146] 


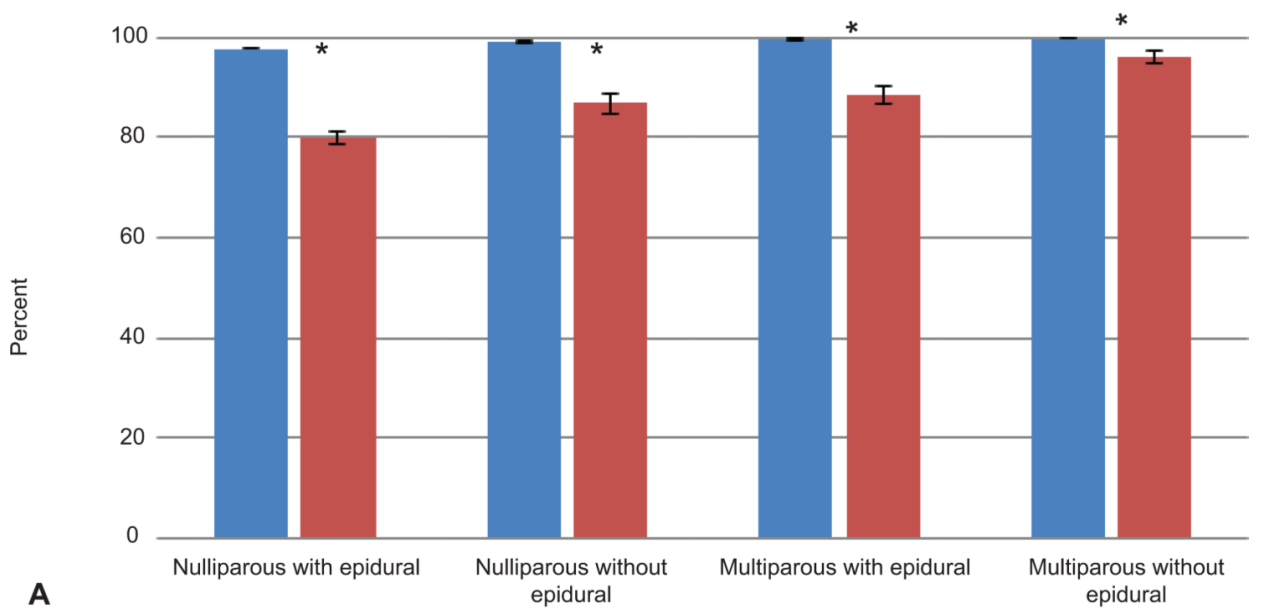

- Within guidelines

- Prolonged second stage

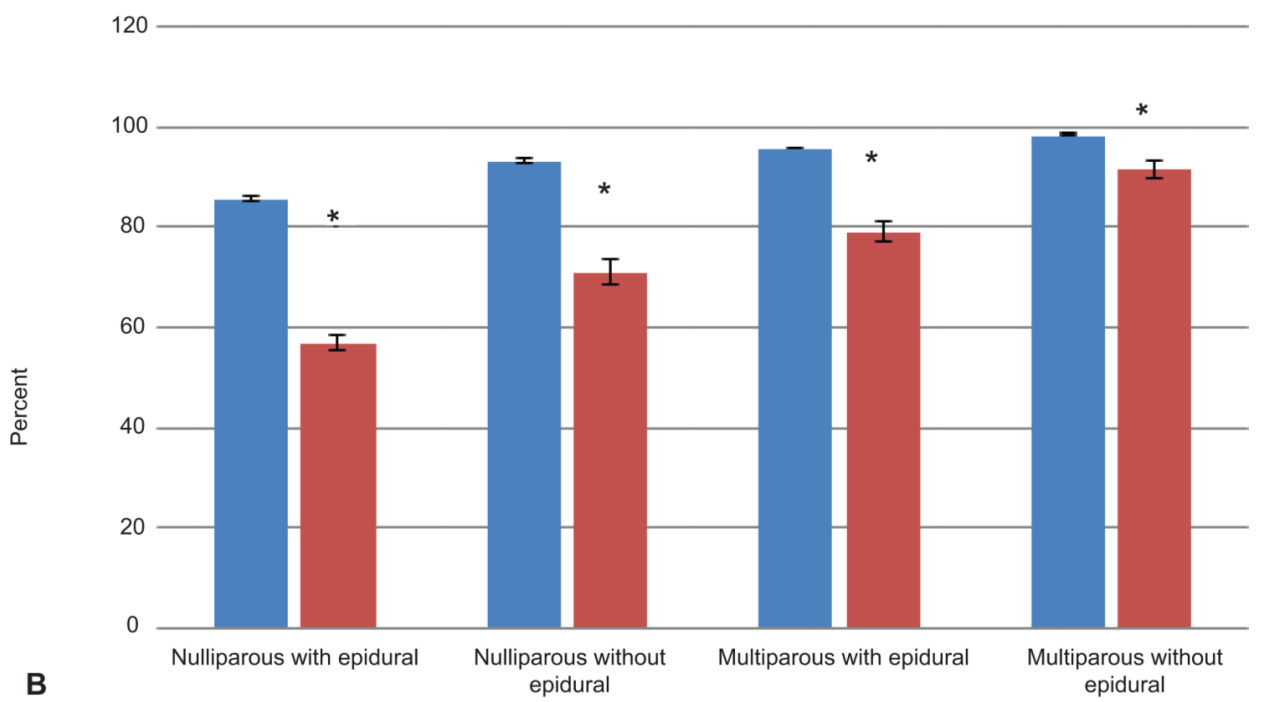

Within guidelines

- Prolonged second stage 
30

25

20

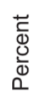

15

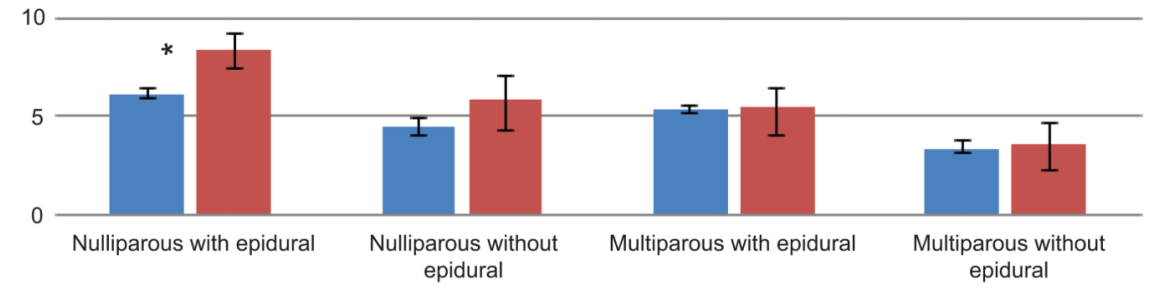

Within guidelines

Prolonged second stage

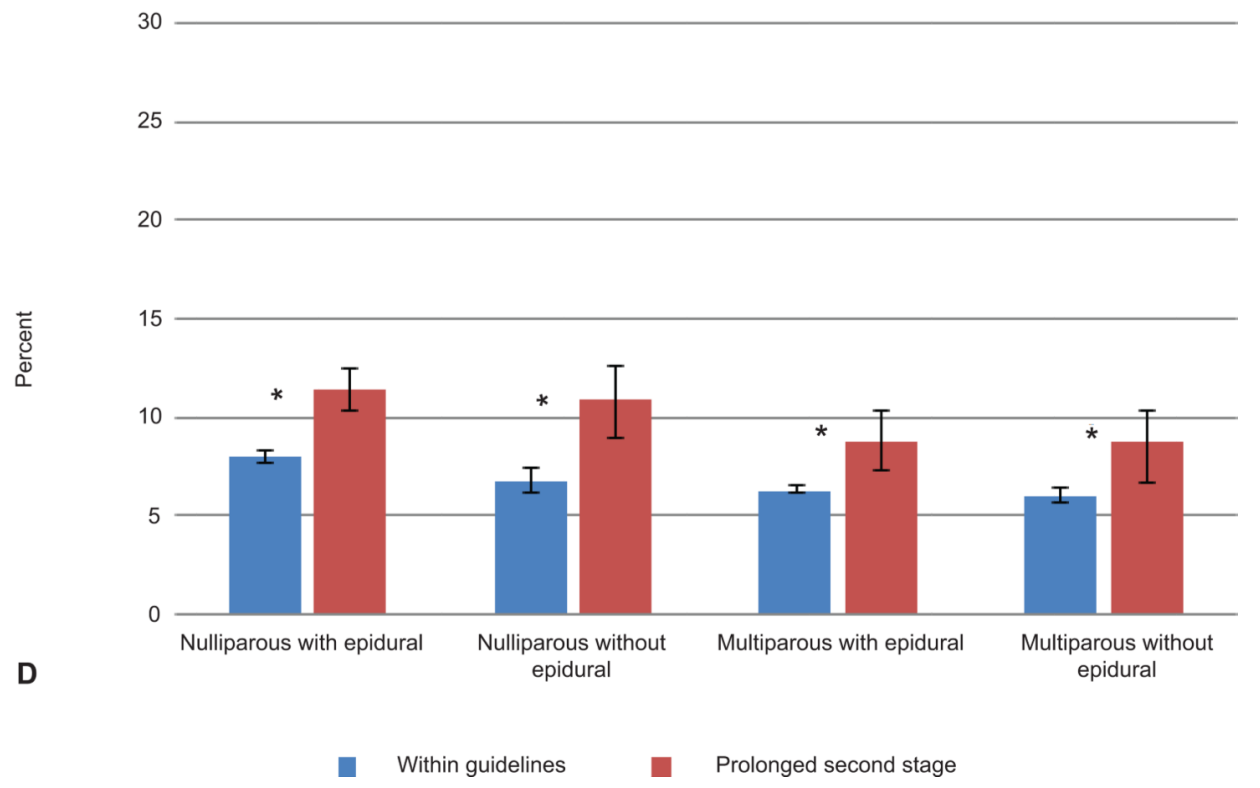

Figure 1.

Mode of Delivery and Neonatal Outcomes According to Duration of Second Stage in Women by Parity and Epidural Status. A. Vaginal delivery; B. Nonoperative vaginal delivery; C. Composite maternal morbidity; D. Composite neonatal morbidity. Prolonged second stage as per American College of Obstetricians and Gynecologists guidelines was defined as: for nulliparous women $>3$ hours with epidural or $>2$ hours without; multiparous women $>2$ hours with epidural or $>1$ hour without. (15) Maternal composite morbidity included postpartum hemorrhage, blood transfusion, cesarean hysterectomy, endometritis, or 
intensive care unit admission (ICU). Neonatal composite morbidity included shoulder dystocia, 5 minute Apgar $<4$, need for continuous positive airway pressure resuscitation or higher, neonatal ICU admission, sepsis, pneumonia, hypoxic-ischemic encephalopathy/ periventricular leukomalacia, seizure, intracranial hemorrhage/periventricular hemorrhage, asphyxia, or perinatal death. Error bars indicate $95 \%$ confidence intervals and asterisks are for significance in the unadjusted models. All associations remained significant after controlling for maternal race, BMI, insurance and region. (Note that unadjusted composite maternal morbidity rates were not higher for multiparous women with prolonged second stage, but there was a significantly increased odds for multiparous women with an epidural after adjustment.) 


\begin{tabular}{|c|c|c|c|c|c|c|c|c|c|c|c|c|c|c|c|c|c|c|c|c|c|c|}
\hline $\bar{\pi}$ & 2 & $\begin{array}{l}\vec{\sigma} \\
\dot{\sigma}\end{array}$ & 旾 & 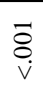 & & & & & & 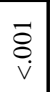 & & & & $\frac{\text { nे }}{0}$ & 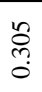 & $\mid \begin{array}{l}\frac{1}{\infty} \\
0 \\
0\end{array}$ & స్తి & 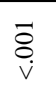 & ¿̊: & $\frac{\widehat{\hat{a}}}{0}$ & ¿̊ & $\bar{g}$ \\
\hline 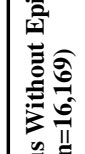 & 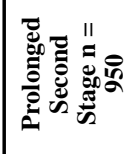 & $\begin{array}{l}\sigma \\
\hat{b} \\
0 \\
\stackrel{d}{0} \\
\end{array}$ & 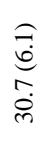 & & 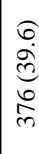 & $\begin{array}{l}\stackrel{0}{0} \\
\stackrel{d}{0} \\
\text { तె }\end{array}$ & 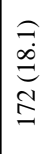 & 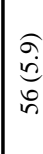 & $\begin{array}{c}\infty \\
\stackrel{\infty}{\sigma} \\
\sigma\end{array}$ & & 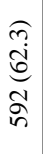 & 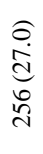 & 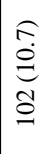 & 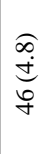 & 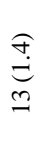 & 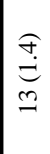 & $\begin{array}{l}\widehat{\hat{d}} \\
\text { d } \\
\frac{\infty}{d}\end{array}$ & $\begin{array}{l}\stackrel{a}{Q} \\
\text { d } \\
\stackrel{r}{r}\end{array}$ & $\begin{array}{l}\frac{8}{0} \\
8 \\
0 \\
8 \\
2\end{array}$ & $\begin{array}{l}6 \\
\text { i } \\
\text { ñ } \\
8 \\
\text { n. }\end{array}$ & 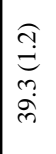 & 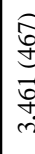 \\
\hline
\end{tabular}

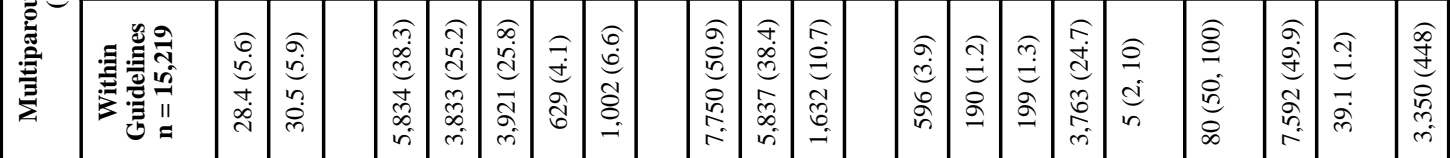

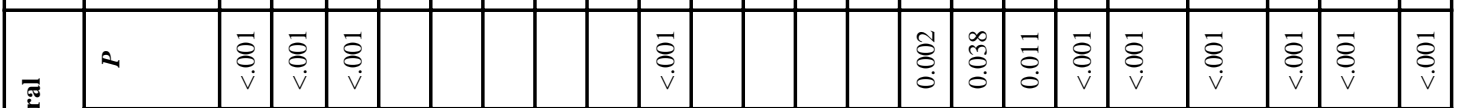

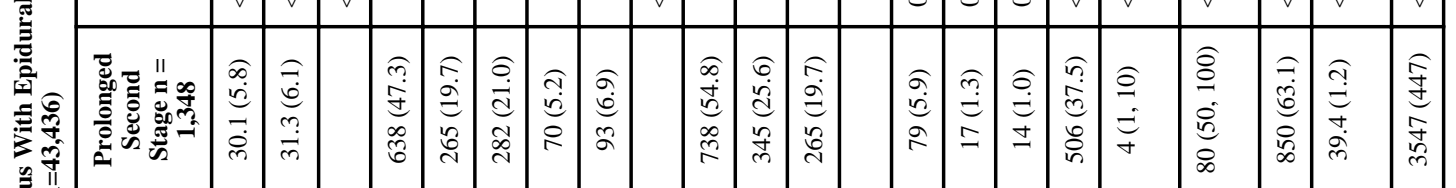

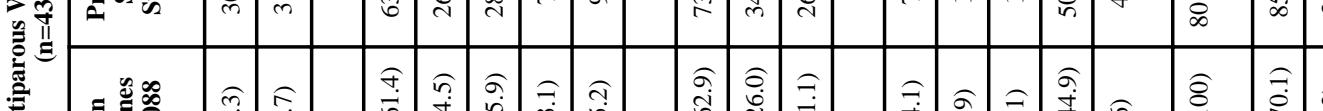

\begin{tabular}{|c|c|c|c|c|c|c|c|c|c|c|c|c|c|c|c|c|c|c|c|}
\hline 党象 & 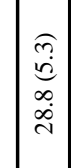 & $\begin{array}{l}\hat{E} \\
\dot{b} \\
m \\
\tilde{n} \\
0\end{array}$ & & 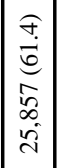 & 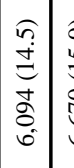 & 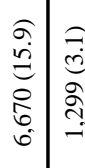 & 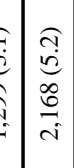 & & 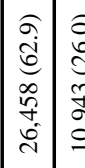 & 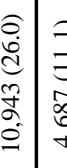 & & 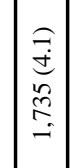 & $\begin{array}{l}\hat{\sigma} \\
e \\
\infty \\
\infty \\
\tilde{c}\end{array}$ & $\begin{array}{l}= \\
\tilde{a} \\
\tilde{d} \\
\infty \\
\infty\end{array}$ & $\begin{array}{l}\sigma \\
\dot{j} \\
\dot{j} \\
\infty \\
\infty \\
\infty \\
\infty \\
0\end{array}$ & $\begin{array}{l}6 \\
\dot{=} \\
m\end{array}$ & & & \begin{tabular}{|l}
$\widehat{\overbrace{}}$ \\
$\stackrel{\Xi}{\Xi}$ \\
$\stackrel{0}{\circ}$ \\
$\dot{\rho}$
\end{tabular} \\
\hline 2 & $\mid \begin{array}{l}\vec{z} \\
\dot{v}\end{array}$ & 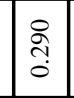 & 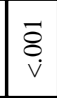 & & & & & $\begin{array}{l}\vec{z} \\
\dot{v}\end{array}$ & & & & $\mid \begin{array}{c}\infty \\
\stackrel{9}{0} \\
0\end{array}$ & 递 & $\begin{array}{l}0 \\
\check{0} \\
0\end{array}$ & 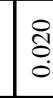 & & & & $\underset{v}{\vec{\delta}}$ \\
\hline
\end{tabular}

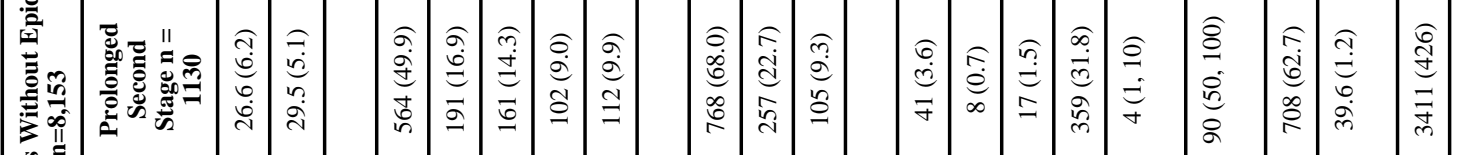

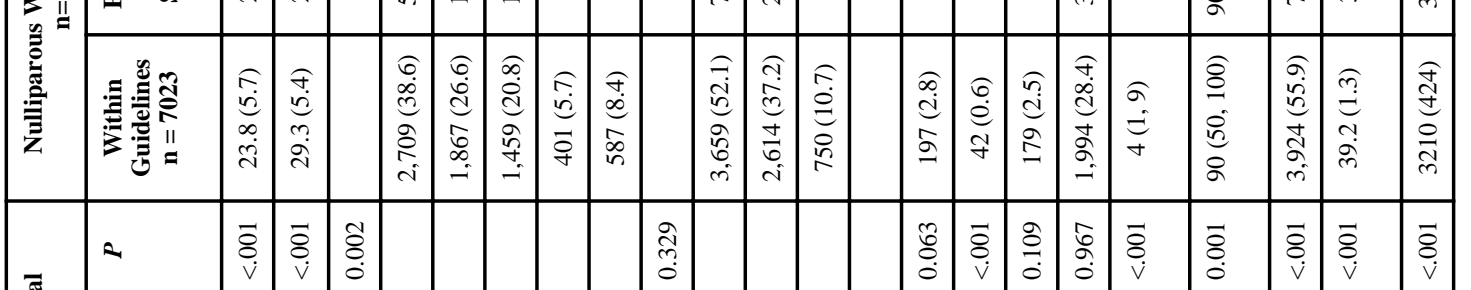

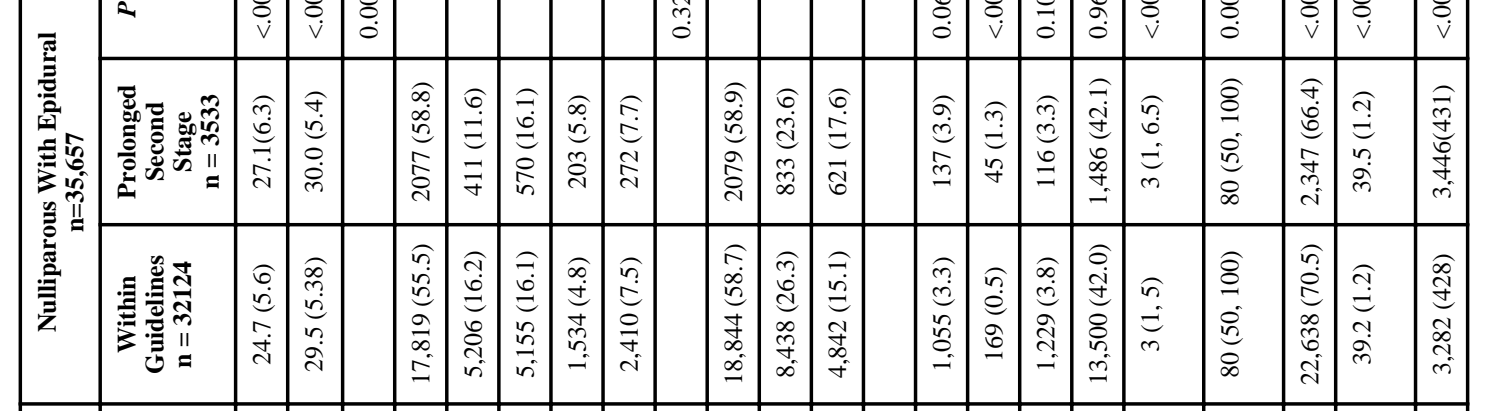




\begin{tabular}{|c|c|c|c|c|c|c|c|c|c|c|c|c|c|c|c|c|c|c|c|c|c|c|c|c|}
\hline & & 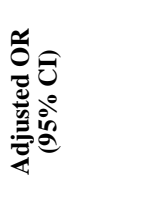 & & & & 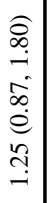 & 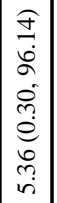 & 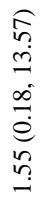 & 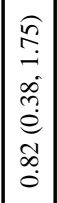 & 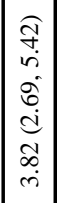 & 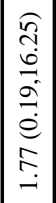 & & 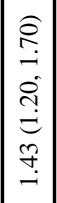 & 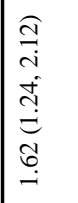 & ' & & & 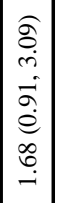 & 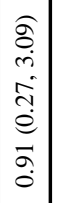 & 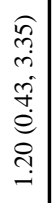 & 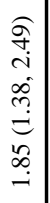 & 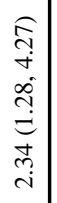 & 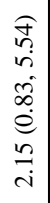 & \\
\hline & 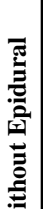 & 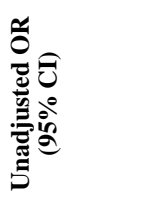 & & & 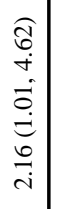 & 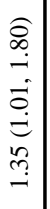 & 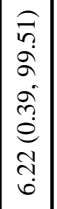 & 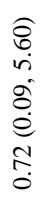 & 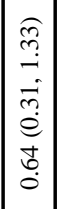 & 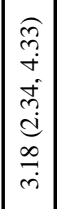 & 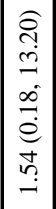 & & 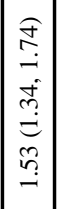 & 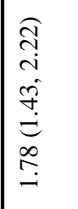 & 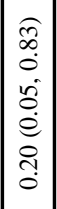 & & & 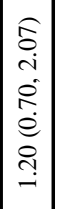 & 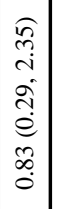 & $\begin{array}{l}\hat{\sigma} \\
\dot{c} \\
\stackrel{0}{0} \\
\stackrel{0}{0} \\
\stackrel{0}{0}\end{array}$ & 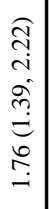 & 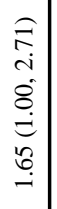 & 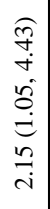 & 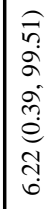 \\
\hline & 峁 & 2 & & & $\begin{array}{l}0 \\
0 \\
0 \\
0\end{array}$ & 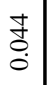 & $\frac{\circ}{\circ}$ & 号 & 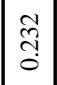 & $\mid \begin{array}{l}\vec{\delta} \\
\dot{v}\end{array}$ & 兽 & & $\begin{array}{l}\vec{\delta} \\
\dot{v}\end{array}$ & $\begin{array}{l}\vec{\delta} \\
\dot{v}\end{array}$ & $\begin{array}{l}0 \\
0 \\
0 \\
0\end{array}$ & 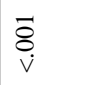 & & $\left|\begin{array}{l}0 \\
0 \\
0 \\
0\end{array}\right|$ & 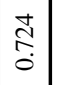 & $\begin{array}{l}\overrightarrow{0} \\
\vdots \\
0\end{array}$ & $\bar{\delta}_{i}$ & $\begin{array}{l}\stackrel{a}{0} \\
0 \\
0\end{array}$ & $\begin{array}{l}\tilde{o} \\
0 \\
0\end{array}$ & $\stackrel{\circ}{\circ}$ \\
\hline 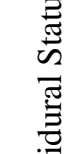 & $\overline{\bar{z}}$ & 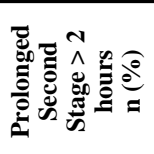 & $\begin{array}{l}\hat{\rho} \\
\stackrel{2}{\Xi} \\
\stackrel{0}{\Xi}\end{array}$ & & $\begin{array}{l}\hat{E} \\
\dot{e} \\
\sigma\end{array}$ & $\begin{array}{c}c \\
\vec{c} \\
\infty \\
i n\end{array}$ & $\stackrel{\widehat{e}}{\underline{e}}$ & $\widehat{\widehat{e}}$ & $\mid \begin{array}{l}\stackrel{f}{\rightleftarrows} \\
\underset{\infty}{ \pm}\end{array}$ & \begin{tabular}{|l|}
6 \\
0 \\
6 \\
6 \\
0
\end{tabular} & $\mid \begin{array}{c}\widehat{\widehat{g}} \\
\stackrel{\varrho}{-}\end{array}$ & $\hat{\varrho}$ & 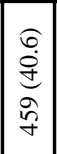 & $\begin{array}{l}\widehat{\sigma} \\
\stackrel{\Xi}{9} \\
\varrho\end{array}$ & $\underset{\substack{\widehat{C} \\
\mathrm{~N}}}{ }$ & $\begin{array}{l}f \\
d \\
d \\
m\end{array}$ & & $\stackrel{n}{\stackrel{n}{\rightleftarrows}}$ & $\begin{array}{l}f \\
\stackrel{f}{e} \\
\vec{f}\end{array}$ & 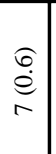 & $\begin{array}{l}6 \\
\infty \\
\infty \\
\vdots\end{array}$ & $\begin{array}{l}\stackrel{\infty}{\infty} \\
\stackrel{i}{\Xi} \\
\stackrel{i}{1}\end{array}$ & $\begin{array}{l}\hat{\sigma} \\
\hat{e} \\
\varrho\end{array}$ & $\widehat{\overbrace{}}$ \\
\hline $\begin{array}{l}\text { 푀 } \\
\text { ลે } \\
\text { ฮี } \\
\text { हี }\end{array}$ & & 总 vi & 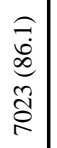 & & 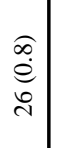 & $\begin{array}{l}\hat{\sigma} \\
\dot{\vec{c}} \\
\vec{\lambda}\end{array}$ & $\begin{array}{c}\widehat{\sigma} \\
\stackrel{e}{e} \\
-\end{array}$ & $\begin{array}{c}\text { đี } \\
\stackrel{0}{\varrho}\end{array}$ & 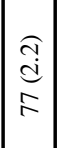 & 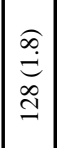 & $\begin{array}{c}\hat{\bar{e}} \\
\mathrm{e} \\
\text { n }\end{array}$ & 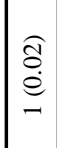 & 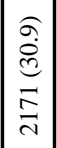 & $\begin{array}{l}\widehat{\alpha} \\
\dot{d} \\
\stackrel{g}{q}\end{array}$ & $\begin{array}{l}\frac{\hat{g}}{e} \\
\bar{b}\end{array}$ & 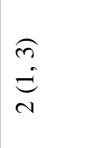 & & $\underset{\infty}{\stackrel{\overbrace{}}{\leftrightarrows}}$ & 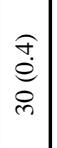 & $\begin{array}{l}\mathfrak{n} \\
\stackrel{n}{2} \\
\approx \\
m\end{array}$ & 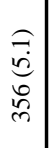 & 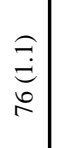 & 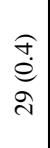 & $\underset{0}{\stackrel{0}{0}}$ \\
\hline 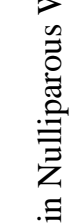 & & 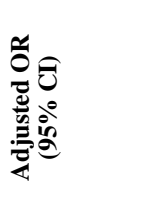 & & & 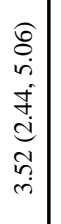 & 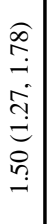 & & $\begin{array}{l}\widehat{c} \\
- \\
0 \\
\stackrel{0}{0} \\
0 \\
o \\
0 \\
0\end{array}$ & 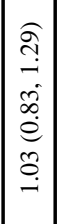 & 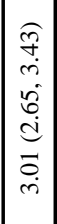 & 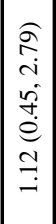 & 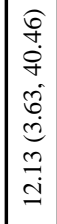 & $\mid \begin{array}{c}0 \\
0 \\
0 \\
0 \\
0 \\
0 \\
0 \\
0 \\
0 \\
0\end{array}$ & 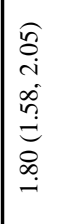 & 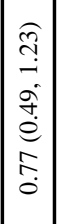 & & & 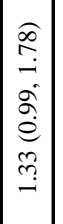 & 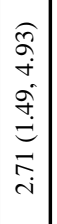 & 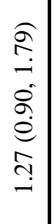 & 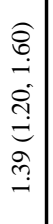 & $\begin{array}{l}\hat{尺} \\
i \\
o \\
\dot{0} \\
\stackrel{0}{0} \\
\infty \\
\dot{i} \\
i\end{array}$ & 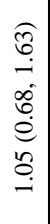 & \\
\hline 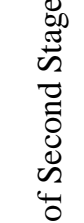 & 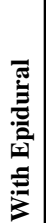 & 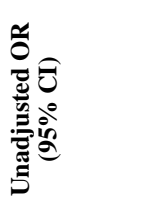 & & & 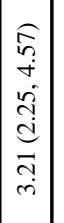 & 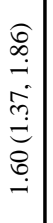 & 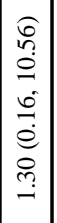 & 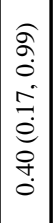 & 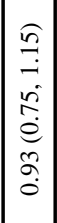 & 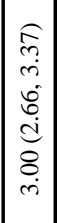 & 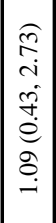 & 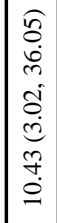 & $\mid$\begin{tabular}{c|c}
0 \\
$\infty$ \\
0 \\
0 \\
0 \\
0 \\
0 \\
0 \\
0 \\
0 \\
0
\end{tabular} & 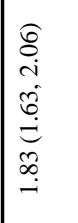 & 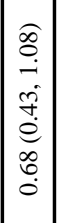 & & & 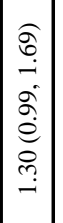 & 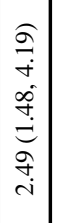 & 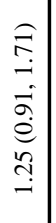 & 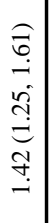 & $\begin{array}{l}\hat{Q} \\
i \\
i \\
\stackrel{i}{i} \\
n \\
i \\
i\end{array}$ & 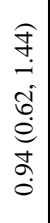 & \\
\hline 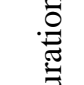 & 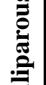 & 2 & & & 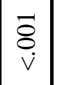 & $\begin{array}{l}\vec{\sigma} \\
\dot{v}\end{array}$ & $\begin{array}{l}1 \\
0 \\
0 \\
0\end{array}$ & $\mid \begin{array}{l}\infty \\
0 \\
0 \\
0 \\
0\end{array}$ & $\mid$\begin{tabular}{|l}
$\infty$ \\
0 \\
0 \\
0 \\
0
\end{tabular} & $\begin{array}{l}\overrightarrow{8} \\
\dot{v}\end{array}$ & $\begin{array}{l}\hat{\partial} \\
\infty \\
0 \\
0\end{array}$ & $\vec{\delta}_{i}$ & $\begin{array}{l}\vec{\Xi} \\
\dot{v}\end{array}$ & $\underset{v}{\vec{g}}$ & 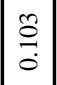 & 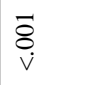 & & $\begin{array}{l}0 \\
0 \\
0 \\
0 \\
0\end{array}$ & $\mid$\begin{tabular}{|}
$\vec{\Xi}$ \\
$\dot{v}$
\end{tabular} & \begin{tabular}{l}
$n$ \\
\hdashline \\
0
\end{tabular} & $\begin{array}{l}\bar{z} \\
\dot{v}\end{array}$ & $\vec{o}_{i}$ & $\begin{array}{l}\stackrel{2}{2} \\
\stackrel{2}{0}\end{array}$ & \\
\hline 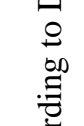 & & 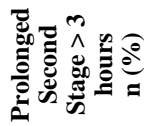 & 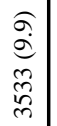 & & 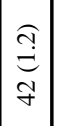 & $\begin{array}{l}\hat{\sigma} \\
\dot{b} \\
\hat{\sigma}\end{array}$ & $\begin{array}{c}\hat{0} \\
\stackrel{0}{e} \\
-\end{array}$ & $\stackrel{\widehat{\vartheta}}{\stackrel{\varepsilon}{n}}$ & \begin{tabular}{l|}
$\stackrel{\Im}{+}$ \\
$\stackrel{+}{ \pm}$ \\
a
\end{tabular} & 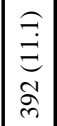 & $\begin{array}{c}\widehat{\widehat{c}} \\
\stackrel{e}{\varepsilon} \\
n\end{array}$ & $\begin{array}{c}\widehat{\tau} \\
\stackrel{e}{n}\end{array}$ & 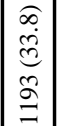 & 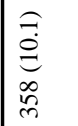 & 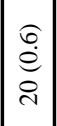 & $\begin{array}{c}f \\
d \\
d \\
d\end{array}$ & & 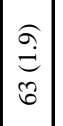 & $\begin{array}{c}n \\
\tilde{n} \\
e \\
\infty \\
-\end{array}$ & 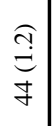 & $\begin{array}{c}\widehat{c} \\
\infty \\
\infty \\
\infty \\
\infty \\
c\end{array}$ & $\begin{array}{c}\sigma \\
d \\
d \\
\sigma\end{array}$ & 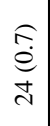 & $\stackrel{\varrho}{\circ}$ \\
\hline 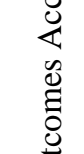 & & 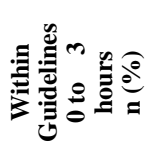 & 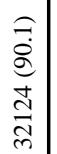 & & 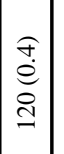 & 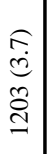 & $\begin{array}{l}\text { त्ठ } \\
\stackrel{e}{2}\end{array}$ & 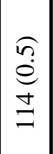 & 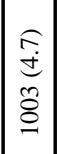 & 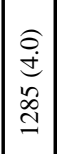 & 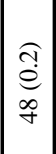 & $\begin{array}{l}\widehat{\delta} \\
\stackrel{\delta}{e} \\
\text { n }\end{array}$ & 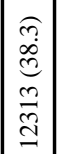 & 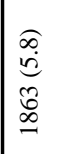 & 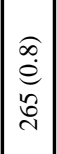 & $\begin{array}{l}\hat{m} \\
\dot{d} \\
\text { n }\end{array}$ & & 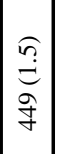 & 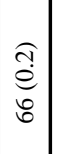 & 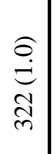 & $\begin{array}{l}\sigma \\
\hat{\sigma} \\
\widetilde{\sigma} \\
\infty \\
\sigma\end{array}$ & 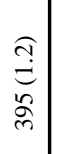 & $\begin{array}{l}\hat{E} \\
\stackrel{\dot{\theta}}{\tilde{v}}\end{array}$ & 宊 \\
\hline 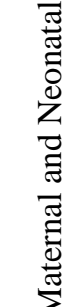 & & & $=$ & 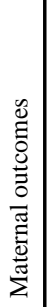 & 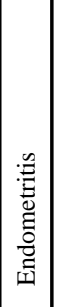 & 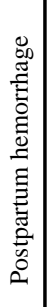 & 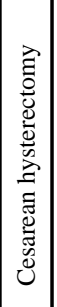 & 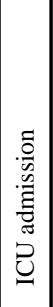 & 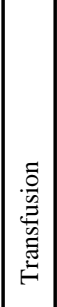 & 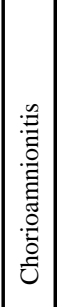 & 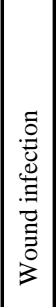 & 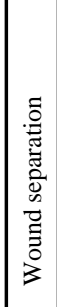 & 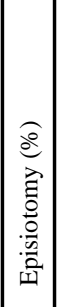 & 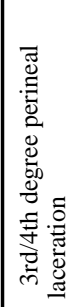 & 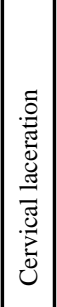 & 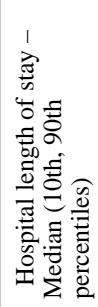 & 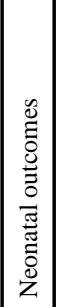 & 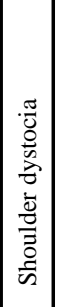 & 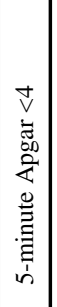 & 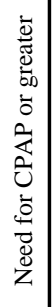 & 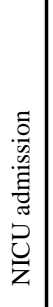 & $\begin{array}{l}\frac{\infty}{0} \\
\overline{0} \\
\ddot{\omega}\end{array}$ & 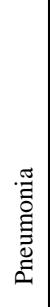 & 点 \\
\hline
\end{tabular}




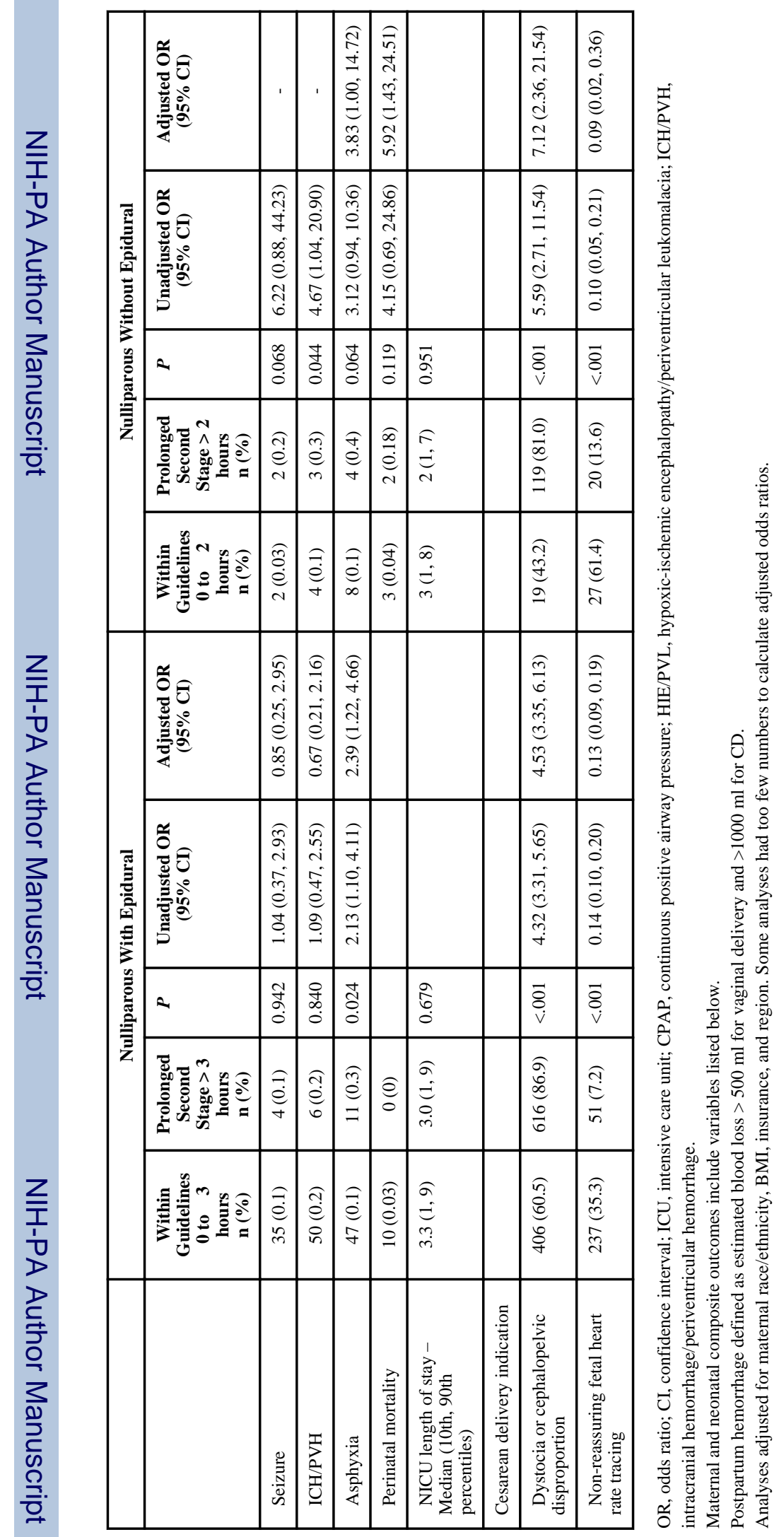




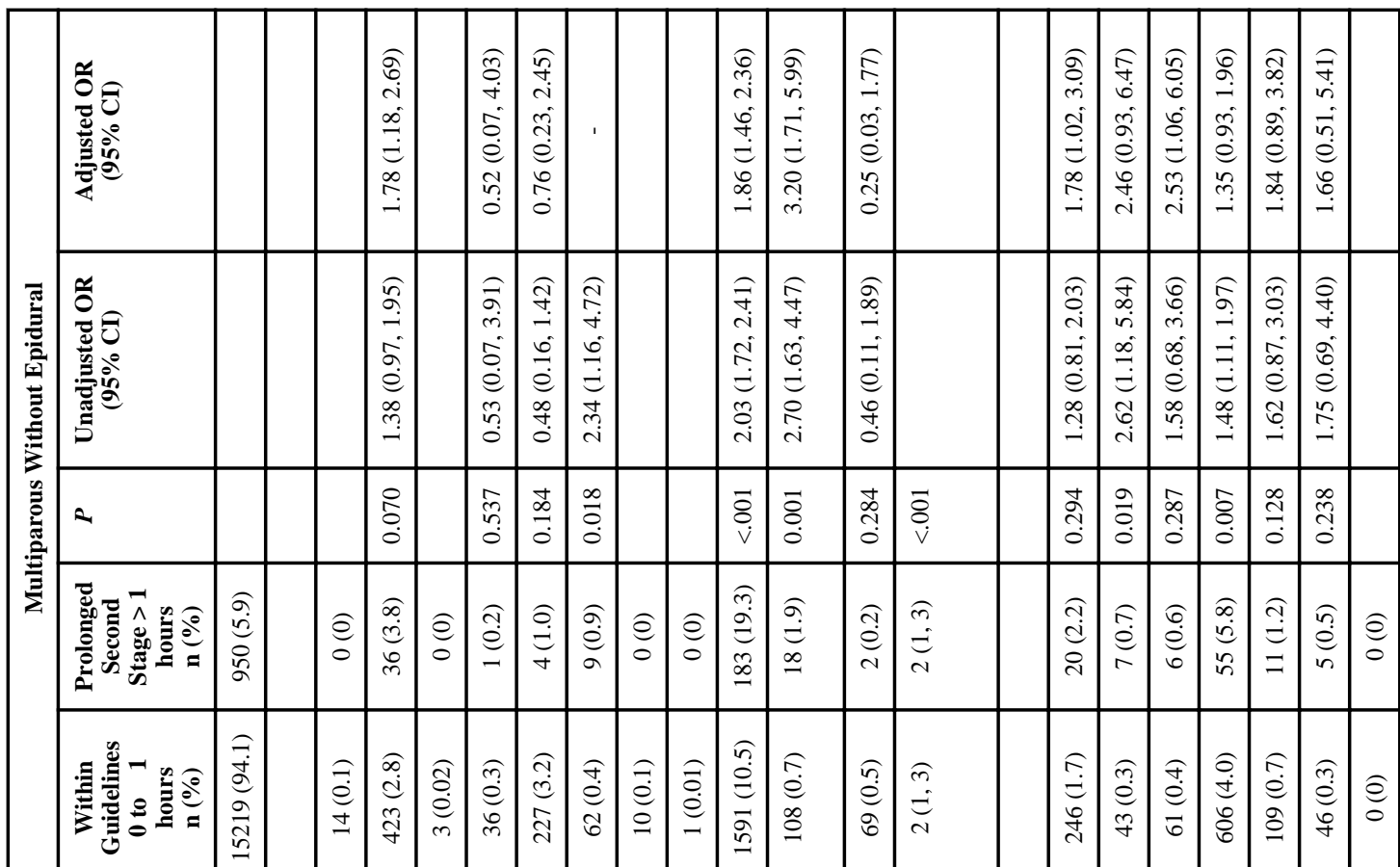

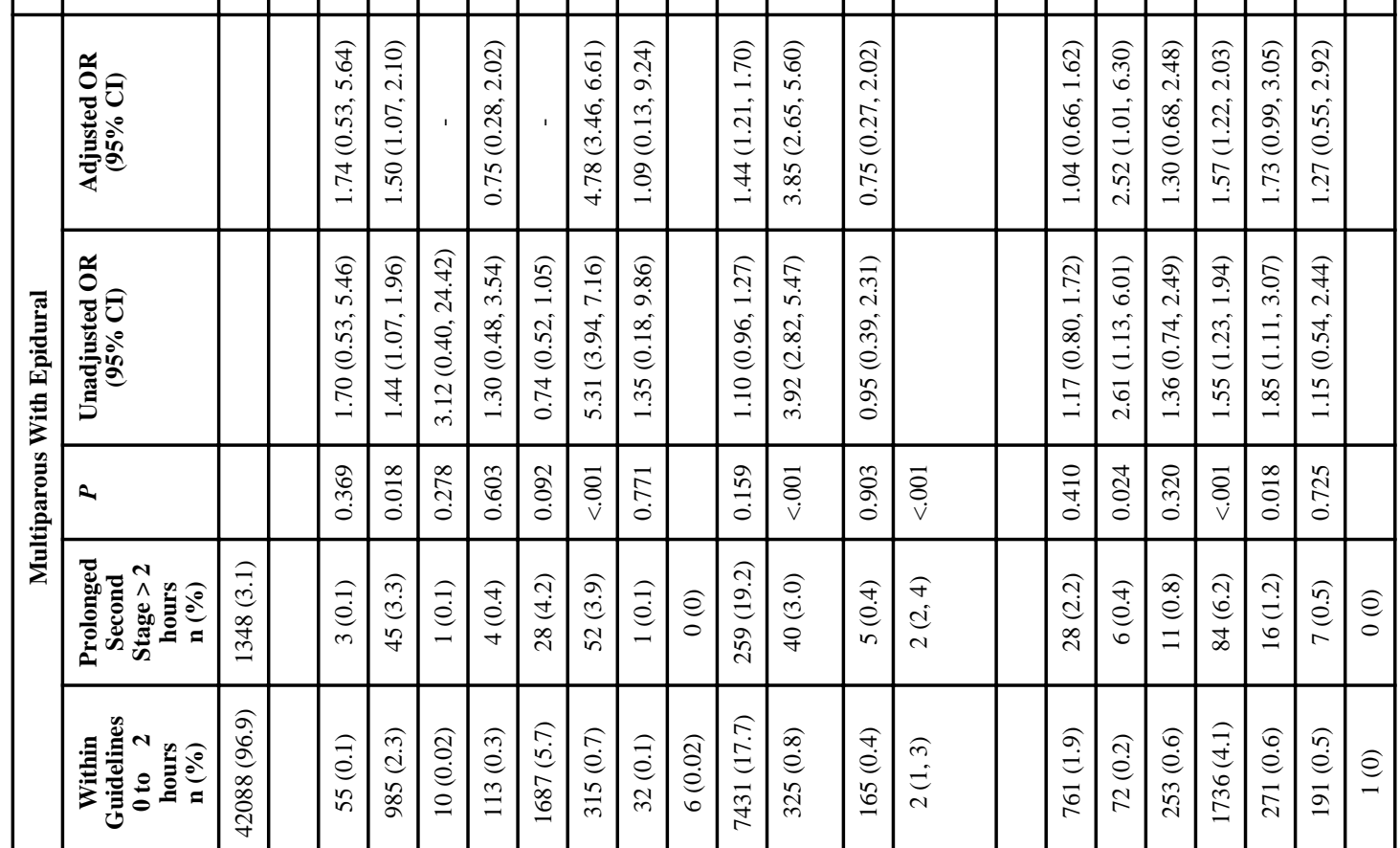

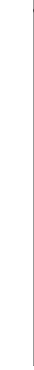
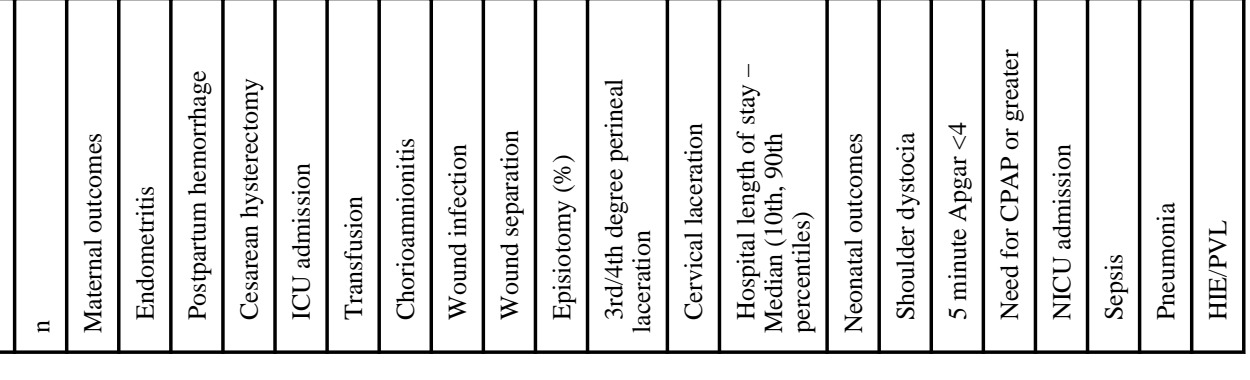


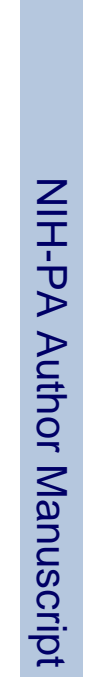

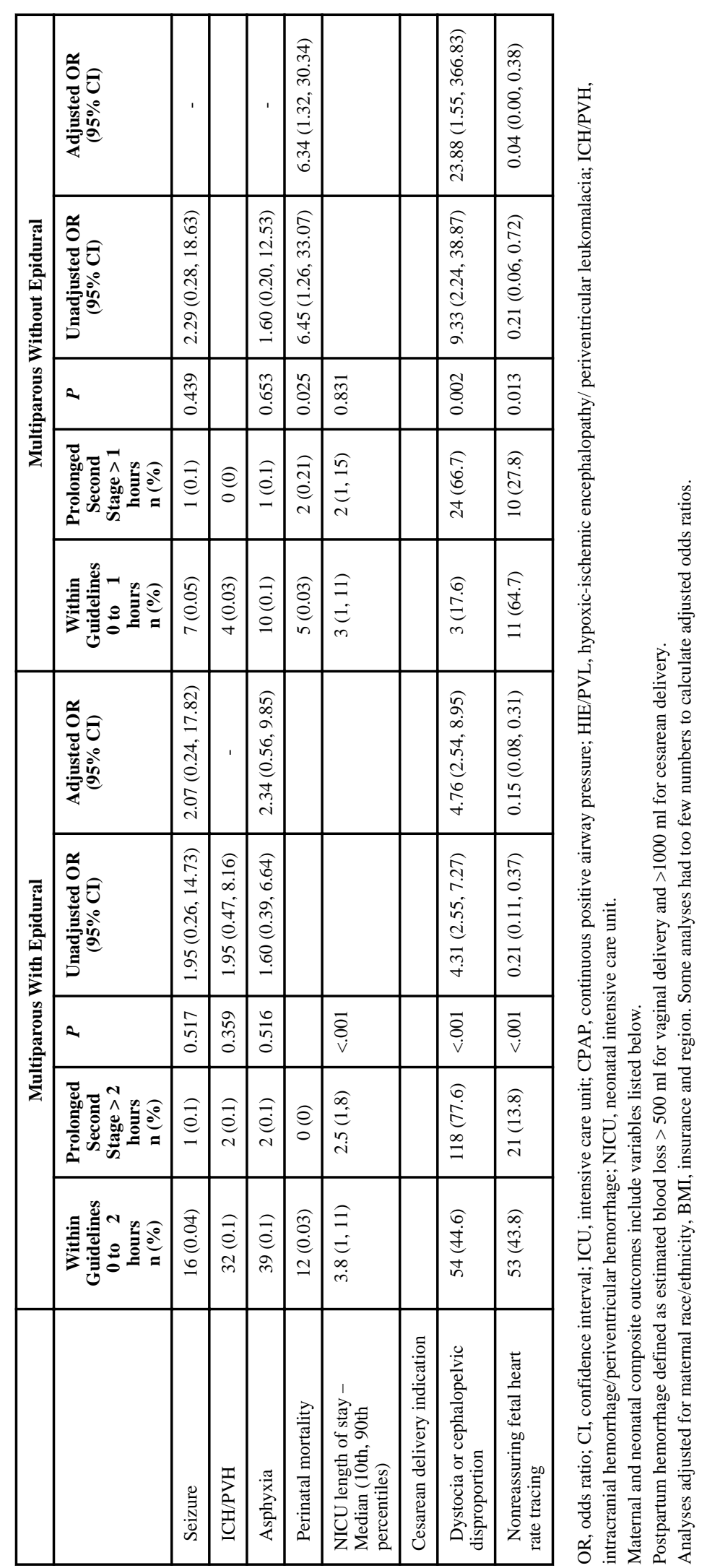

